\title{
Erratum to: Study on Creep Properties for TIG Welded Joints of CLAM Steel
}

\author{
Xin Zhang $^{1} \cdot$ Yucheng Lei ${ }^{13} \cdot$ Ling Chen ${ }^{2} \cdot$ Fei Huang ${ }^{1} \cdot$ Qiang Zhu $^{1}$
}

Published online: 11 November 2015

(c) Springer Science+Business Media New York 2015

Erratum to: J Fusion Energ (2015)

DOI 10.1007/s10894-015-0024-3

The original version of this article unfortunately contained a mistake. One of the author's affiliations was missed. It is now included with this erratum. The authors regret for the inconvenience caused in this regard.

The corrections do not affect any results or conclusions of the published work.

The online version of the original article can be found under doi:10.1007/s10894-015-0024-3.

Yucheng Lei

marvinzhangxin@163.com

1 School of Material Science and Engineering of Jiangsu University, No. 301 Xuefu Rd, Zhenjiang, Jiangsu, China

2 School of Material Science and Engineering of Southeast University, Nanjing, China

3 State Key Laboratory of Advanced Welding and Joining, Harbin Institute of Technology, Harbin 150001, China 